\title{
Cutaneous Manifestations of Nutritional Excess: Pathophysiologic Effects of Hyperglycemia and Hyperinsulinemia on the Skin
}

\author{
Steven A. Svoboda, BS; Bridget E. Shields, MD
}

\section{PRACTICE POINTS}

- Dermatologists should be aware of common cutaneous conditions associated with chronic hyperglycemia and hyperinsulinemia, such as acanthosis nigricans, diabetic dermopathy, scleredema diabeticorum, ichthyosiform skin changes, acrochordons, and keratosis pilaris.

- More rare cutaneous pathologies related to chronically elevated blood glucose and/or insulin levels include necrobiosis lipoidica, bullosis diabeticorum, and generalized granuloma annulare.

- The cutaneous manifestations of persistent hyperglycemia and hyperinsulinemia may precede a formal diagnosis of diabetes mellitus and may be the first signs of metabolic derangement.

- Early recognition and management of these cutaneous conditions can help maximize patient quality of life and avoid long-term sequelae associated with insulin resistance and prolonged hyperglycemia.

Hyperglycemia is defined by excess blood glucose and, when persistent, may lead to prediabetic and diabetic states. Insulin is a hormone produced by the beta cells of the pancreas in response to elevated blood glucose. Dysregulated insulin secretion or clearance results in hyperinsulinemia, which also is closely associated with type 2 diabetes mellitus (T2DM) and metabolic disturbances. Hyperglycemia and hyperinsulinemia are endemic within the United States and impart considerable morbidity and mortality. Cutaneous manifestations of chronic hyperglycemia and hyperinsulinemia include acanthosis nigricans (AN), diabetic dermopathy (DD), scleredema diabeticorum (SD), ichthyosiform skin changes, acrochordons, and keratosis pilaris (KP). Necrobiosis lipoidica (NL), bullosis diabeticorum (BD), and generalized granuloma annulare (GA) are more rarely reported in association with hyperglycemia and hyperinsulinemia; however, the strength of these associations remains unclear. It is crucial for dermatologists to recognize these cutaneous manifestations, as they may be the first signs of metabolic syndrome and insulin resistance. Early identification and management of these conditions is key to improving patient health outcomes and reducing health care costs. Herein, we review the clinical presentations of these conditions and their underlying pathophysiologic mechanisms.

Cutis. 2021;107:74-78.

V utritional dermatoses are classically associated with dietary nutrient deficiencies; however, cutaneous disease as a consequence of nutrient excess often is overlooked. Chronic hyperglycemia and hyperinsulinemia resulting from excess carbohydrate intake may be implicated in a number of cutaneous pathologies, of which every dermatologist should be aware. ${ }^{1-3}$

Although diabetic patients exhibit many cutaneous manifestations of excess carbohydrate consumption, the absence of a diagnosis of type 2 diabetes mellitus (T2DM) does not necessarily preclude them. ${ }^{4-6}$ Emerging evidence now highlights the development of insulin resistance well before a patient ever meets the diagnostic criteria for T2DM. ${ }^{7,8}$ Cutaneous disease can provide early insight into a patient's glucose tolerance and may be the first sign of metabolic derangement. Prompt recognition of these cutaneous alterations and management of the patient's underlying

Mr. Svoboda is from the Virginia Tech Carilion School of Medicine, Roanoke. Dr. Shields is from the Department of Dermatology, University of Wisconsin School of Medicine and Public Health, Madison.

The authors report no conflict of interest.

Correspondence: Bridget E. Shields, MD, 1 S Park St, University of Wisconsin School of Medicine and Public Health, Department of Dermatology, Madison, WI 53711 (bshields@dermatology.wisc.edu).

doi:10.12788/cutis.0173 
systemic disease can improve their quality of life and help prevent severe systemic complications associated with insulin resistance and impaired glucose tolerance.

The aim of this review is to highlight both common and rare cutaneous manifestations associated with the persistent consumption of high glycemic load diets, resultant hyperglycemic and hyperinsulinemic states, and the pathophysiologic mechanisms that underlie them.

\section{Acanthosis Nigricans}

Acanthosis nigricans (AN) is a highly prevalent cutaneous finding in individuals with insulin resistance that clinically presents as thickened, hyperpigmented, velvety plaques on the intertriginous and flexural surfaces. The most frequently involved sites include the neck, axillae (Figure), and inframammary and inguinal folds. Black and Hispanic patients most commonly are affected. Although classically associated with T2DM, AN also can be observed in normoglycemic individuals. ${ }^{7-9}$ One recent study reported the rate of $\mathrm{AN}$ to be $36 \%$ in a cohort of middle-aged patients ( $N=320)$ with normal fasting blood glucose levels, while the rate of AN in matched patients with hyperglycemia (prediabetes and T2DM) was approximately 50\%. ${ }^{7}$ Quantification of insulin resistance was performed using the homeostatic model assessment of insulin resistance index. Interestingly, the specificity for insulin resistance in normoglycemic and hyperglycemic subjects with AN was $85 \%$ and $90 \%$, respectively. ${ }^{7}$ These findings suggest that AN may serve as a convenient surrogate marker for subclinical insulin resistance, a conclusion that has been reported in a series of previous studies. ${ }^{8-10}$

Although the pathogenesis of AN has not been fully elucidated, it is known that persistently elevated blood glucose triggers continual secretion of insulin and

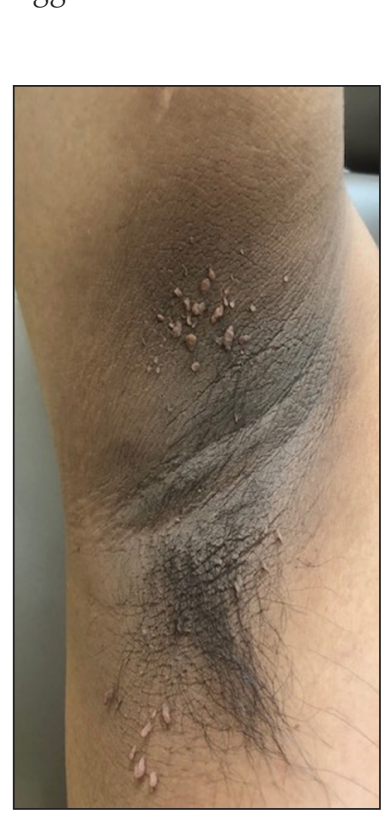

Acanthosis nigricans of the axilla with associated acrochordons in a patient with poorly controlled type 2 diabetes mellitus. insulinlike growth factor 1 (IGF-1), which results in the overstimulation of insulin and IGF-1 receptors on keratinocytes and dermal fibroblasts through direct and indirect pathways. ${ }^{11,12}$ The resultant cellular proliferation can be observed histologically in the forms of orthokeratotic hyperkeratosis and papillomatosis, as occurs in AN.11,13 Further supporting the association between elevated insulin and AN are reports of AN developing at sites of repeated insulin injection as well as genetic mutations in the insulin receptor resulting in severe AN in children. ${ }^{14-16}$

The treatment of AN ultimately focuses on improving glycemic control and reducing insulin resistance through lifestyle modification and pharmacotherapy with agents such as metformin. ${ }^{11,13}$ Dermatologic treatment with oral and topical keratolytic agents such as isotretinoin and other retinoids, salicylic acid, urea, or ammonium lactate may be used, but their efficacy generally has been limited. ${ }^{11,13,17,18}$

\section{Diabetic Dermopathy}

Diabetic dermopathy (DD), commonly known as shin spots, refers to the red-brown, atrophic, circinate macules and patches that often appear on the lower extremities in patients with T2DM. Although the pretibial area is the most frequently involved site, other areas of bony prominence such as the forearms can be affected. The prevalence of $\mathrm{DD}$ in the diabetic population can be exceedingly high, with some studies reporting incidence rates greater than $50 \%$, particularly in those with poorly controlled T2DM. ${ }^{19-21}$ Interestingly, DD also has been documented in patients without T2DM and has been postulated to be an early sign of insulin resistance..$^{20,22}$

The pathogenesis of DD remains uncertain, but one proposed mechanism is through microvascular damage caused by hyperglycemia-induced, nonenzymatic glycation, possibly in conjunction with mild trauma, that leads to the deposition of hemosiderin and melanin in the skin. ${ }^{20,23} \mathrm{~A}$ recent study identified increased vascularization of dermopathy lesions when compared with surrounding tissue. ${ }^{24}$ Subcutaneous nerve ischemia and degeneration secondary to diabetic neuropathy also have been postulated as causative. ${ }^{20,23}$ Given the lack of effective therapies and the asymptomatic nature of DD, treatment typically is not pursued. However, DD is associated with other diabetic microvascular complications, including diabetic nephropathy, retinopathy, and neuropathy. For this reason, identification of DD warrants further characterization and management of a patient's underlying diabetes..$^{19,20}$

\section{Scleredema Diabeticorum}

Scleredema diabeticorum (SD) refers to the slowly progressive, painless thickening and woody induration of the neck, shoulders, and upper back in individuals with long-standing, poorly controlled diabetes. The condition is almost exclusively seen in the diabetic population, with prevalence rates reported to be as high as $14 \% .^{25-27}$ Although SD generally is asymptomatic, some individuals may experience restricted mobility and decreased 
sensation in affected areas. ${ }^{25,27,28}$ The diagnosis of SD frequently is missed or ignored clinically. Biopsy can provide diagnostic confirmation of this entity, as histopathology reveals a thickened reticular dermis with an accumulation of collagen and adjacent mucinous infiltrate with no edema or sclerosis. ${ }^{28,29}$

Although the pathogenesis of SD is not well established, it is theorized that the binding of advanced glycation end products (AGEs) to collagen fibers impairs proper cross-linking and degradation by collagenase. ${ }^{29-31}$ It is well known that hyperglycemic conditions can promote endogenous formation of AGEs, which occur when reducing sugar molecules become glycated through a nonenzymatic reaction..$^{30-32}$ The Western diet also is high in preformed AGEs, which are created primarily through certain high-heat cooking methods such as frying and grilling. ${ }^{31,32}$ Hyperglycemia-induced stimulation of fibroblasts also has been proposed as a driver of increased collagen deposition observed histologically in SD. ${ }^{28,29,33}$ Treatment of SD can be difficult, as there are no consistently reported therapies, and even improvement in glycemic control does not appear to reverse this condition. ${ }^{29}$ Case reports have demonstrated some efficacy with various phototherapeutic modalities, including psoralen plus UVA and narrowband UVB phototherapy. ${ }^{34-36}$

\section{Ichthyosiform Skin Changes}

Ichthyosiform skin changes refer to areas of xerosis and scaling that classically present on the anterior distal lower extremities. Although ichthyosiform alterations have been associated with numerous systemic diseases, they often represent an early finding in diabetic patients. ${ }^{27,37}$ The development of ichthyosiform skin changes has been linked to the formation and accumulation of AGEs, which can cause defective cell adhesion in the stratum corneum. ${ }^{37,38}$ Treatment with topical emollients and keratolytics may prove beneficial for the skin but do not improve the underlying systemic condition. ${ }^{39}$

\section{Acrochordons}

Acrochordons (skin tags) are common benign fibroepithelial polyps that classically present on the face, neck, and trunk. The underlying mechanism responsible for the development of acrochordons is uncertain, but the association with insulin resistance and impaired carbohydrate metabolism is well validated. ${ }^{40-46}$ Several large cross-sectional and case-control studies have reported rates of $\mathrm{T} 2 \mathrm{DM}$ ranging from $23 \%$ to $72 \%$ in patients with acrochordons. ${ }^{41,42,47}$ The pathophysiology may involve an increase in tissue and epidermal growth factors driven by elevated serum insulin levels, stimulation of IGF-1 receptors, and a localized proliferation of cutaneous tissue in elastin-poor areas. ${ }^{45,48,49}$ Interestingly, the quantity of acrochordons has been positively correlated with fasting blood glucose levels. Additionally, the presence of 30 or more acrochordons was found to increase the risk of developing T2DM. ${ }^{41}$ Therefore, the presence and number of acrochordons may serve as a convenient indicator of systemic glycemic control and insulin resistance. Screening for T2DM is warranted in individuals without a prior diagnosis who present with multiple acrochordons.

\section{Keratosis Pilaris}

Keratosis pilaris (KP) is a benign skin condition characterized by pink-red, erythematous, monomorphic, follicular papules often seen on the extensor arms, thighs, buttocks, and cheeks. Keratosis pilaris is exceedingly common in the general population but occurs more frequently and with more extensive involvement in those with atopic dermatitis and T2DM. 27,50,51 The mechanism underlying the hyperkeratosis and inflammatory change observed in $\mathrm{KP}$ is not well understood and is likely multifactorial. ${ }^{52,53}$ Hyperandrogenism, as a consequence of hyperinsulinemia, may play an important role in $\mathrm{KP}$, as elevated circulating androgens are known drivers of keratinocyte proliferation of the pilosebaceous unit of hair follicles. ${ }^{52,54}$ Support for this theory includes the clinical exaggeration of KP frequently encountered around puberty when androgen levels peak. ${ }^{55,56}$ Moreover, one study found a higher incidence of KP among adolescent patients with type 1 diabetes mellitus than among healthy age-matched controls. ${ }^{27}$ The most effective treatment of KP appears to be laser therapy, particularly the Q-switched Nd:YAG laser, Numerous topical modalities have been employed to treat KP but exhibit limited efficacy, including mineral oil, tacrolimus, azelaic acid, and salicylic acid, among others. ${ }^{57}$

\section{Necrobiosis Lipoidica}

Necrobiosis lipoidica (NL) is a chronic granulomatous skin condition of unknown origin that presents with well-demarcated, yellow-brown, atrophic patches and plaques often found exclusively on the shins. There is a strong association with type 1 diabetes mellitus, with reported rates ranging from $11 \%$ to $65 \%$ in patients with NL. ${ }^{58-60}$ In a recent retrospective study of 236 patients with NL, $58.5 \%$ of patients had diabetes. ${ }^{61}$ Nevertheless, $\mathrm{NL}$ is a rare entity that affects less than $1 \%$ of the diabetic population. ${ }^{60}$ Given its correlation with diabetes, it has been postulated that the pathogenesis of NL is due to microvascular ischemic changes resulting from prolonged hyperglycemia. ${ }^{60}$ However, studies revealing an increase in blood flow to NL lesions suggest that the condition may instead be attributed to an inflammatory process. ${ }^{62}$ Despite the disfiguring appearance, the lesions of NL often are asymptomatic. Pain or pruritus may develop secondary to ulceration, which occurs in approximately one-third of patients. Although many treatment options have been attempted-including topical and intralesional corticosteroids, immunomodulators, platelet inhibitors, and phototherapy —efficacy is limited. ${ }^{60}$

\section{Bullosis Diabeticorum}

Bullosis diabeticorum (BD) is the abrupt onset of noninflammatory vesicles and bullae developing in the setting 
of diabetes. The prevalence of $\mathrm{BD}$ in the diabetic population ranges from $0.16 \%$ to $0.5 \% .{ }^{63-66}$ Bullosis diabeticorum occasionally has been reported to occur prior to the onset of diabetes, warranting screening hemoglobin $A_{1 c}$ in patients without an established diagnosis of diabetes. ${ }^{67}$ Bullae most commonly present over the acral surfaces, but the lower extremities also are routinely affected. Bullae typically are large and painless, contain clear fluid, and may progress from tense to flaccid over the course of several days. Although histologic analysis reveals nonspecific findings, biopsy may be useful in excluding other bullous disorders. Because $\mathrm{BD}$ is a benign condition that spontaneously resolves over several weeks, treatment rarely is pursued. ${ }^{63,64}$

\section{Generalized Granuloma Annulare}

Generalized granuloma annulare (GA) is an idiopathic inflammatory cutaneous disorder characterized by pinkred, arciform and annular, nonscaly, beaded papules and plaques. Granuloma annulare can be localized or generalized with perforating, patch, and palmoplantar variants. Although the pathogenesis is poorly understood, some studies have demonstrated a correlation between GA and type 1 diabetes mellitus. ${ }^{6-71}$ Generalized GA appears to be most strongly associated with diabetes, and approximately $10 \%$ to $15 \%$ of cases occur in this population. ${ }^{70,72}$ Because GA has been reported to precede the diagnosis of diabetes, patients with generalized or recurrent localized GA should be screened for persistent hyperglycemia with a hemoglobin $\mathrm{A}_{1 \mathrm{c}}$ test. ${ }^{71,73}$ Although some GA is selfresolving, treatment options for persevering GA include topical and intralesional steroids, isotretinoin, dapsone, tacrolimus, antimalarials, biologic medications, and psoralen plus UVA therapy. ${ }^{74}$

\section{Final Thoughts}

Mechanistic links between common cutaneous conditions and persistent hyperglycemic and hyperinsulinemic states are slowly emerging. Hyperglycemia promotes nonenzymatic glycation of the vascular endothelium as well as formation of AGEs that impair cross-linking of collagen in the skin. The consequent microangiopathic damage may lead to cutaneous conditions such as DD, NL, and BD. In addition to microvascular compromise, impaired collagen cross-linking may result in ichthyosiform skin changes and SD. Hyperinsulinemia causes increased circulating levels of IGF-1, which leads to the overactivation of IGF-1 receptors present on fibroblasts and keratinocytes. This aberrant IGF-1 signaling drives cellular hyperproliferation and differentiation, which may be responsible for cutaneous findings such as $\mathrm{AN}, \mathrm{KP}$, and/or acrochordons. An insulin-dependent increase in IGF-1 and androgenic signaling may have implications for hormonally driven inflammatory skin disorders such as acne vulgaris and hidradenitis suppurativa, warranting further investigation.

Physicians should be aware of these dermatologic manifestations and their proposed underlying pathophysiologic mechanisms related to impaired glucose tolerance and insulin resistance. A diagnosis of T2DM is not a prerequisite for metabolic disturbance, and the skin may serve as the first clue to underlying systemic disease. Early identification of these cutaneous conditions may lead to timely patient counseling, lifestyle modification, and/or medical management, preventing the long-term sequelae associated with metabolic disorders.

\section{REFERENCES}

1. Kolb H, Kempf K, Röhling M, et al. Insulin: too much of a good thing is bad. BMC Med. 2020;18:224.

2. Thomas DD, Corkey BE, Istfan NW, et al. Hyperinsulinemia: an early indicator of metabolic dysfunction. J Endocr Soc. 2019;3:1727-1747.

3. Saklayen MG. The global epidemic of the metabolic syndrome. Curr Hypertens Rep. 2018;20:12.

4. Holzer G, Straßegger B, Volc-Platzer B. Cutaneous manifestations of metabolic syndrome. Hautarzt. 2016;67:982-988.

5. Lause M, Kamboj A, Fernandez Faith E. Dermatologic manifestations of endocrine disorders. Transl Pediatr. 2017;6:300-312.

6. Duff M, Demidova O, Blackburn S, et al. Cutaneous manifestations of diabetes mellitus. Clin Diabetes. 2015;33:40-48.

7. Álvarez-Villalobos NA, Rodríguez-Gutiérrez R, González-Saldivar G, et al. Acanthosis nigricans in middle-age adults: a highly prevalent and specific clinical sign of insulin resistance. Int J Clin Pract. 2020;74:E13453.

8. Bhagyanathan M, Dhayanithy D, Parambath VA, et al. Acanthosis nigricans: a screening test for insulin resistance-an important risk factor for diabetes mellitus type-2. J Family Med Prim Care. 2017;6:43-46.

9. Stuart CA, Gilkison CR, Smith MM, et al. Acanthosis nigricans as a risk factor for non-insulin dependent diabetes mellitus. Clin Pediatr (Phila). 1998;37:73-79.

10. Hud JA Jr, Cohen JB, Wagner JM, et al. Prevalence and significance of acanthosis nigricans in an adult obese population. Arch Dermatol. 1992;128:941-944.

11. Hermanns-Lê T, Scheen A, Piérard GE. Acanthosis nigricans associated with insulin resistance: pathophysiology and management. Am J Clin Dermatol. 2004;5:199-203.

12. Cruz PD Jr, Hud JA Jr. Excess insulin binding to insulin-like growth factor receptors: proposed mechanism for acanthosis nigricans. J Invest Dermatol. 1992;98(6 suppl):82S-85S.

13. Higgins SP, Freemark M, Prose NS. Acanthosis nigricans: a practical approach to evaluation and management. Dermatol Online J. 2008;14:2.

14. Buzási K, Sápi Z, Jermendy G. Acanthosis nigricans as a local cutaneous side effect of repeated human insulin injections. Diabetes Res Clin Pract. 2011;94:E34-E36.

15. Tuhan H, Ceylaner S, Nalbantoğlu Ö, et al. A mutation in INSR in a child presenting with severe acanthosis nigricans. J Clin Res Pediatr Endocrinol. 2017;9:371-374.

16. Accili D, Barbetti F, Cama A, et al. Mutations in the insulin receptor gene in patients with genetic syndromes of insulin resistance and acanthosis nigricans. J Invest Dermatol. 1992;98(6 suppl):S77-S81.

17. Romo A, Benavides S. Treatment options in insulin resistance obesityrelated acanthosis nigricans. Ann Pharmacother. 2008;42:1090-1094.

18. Treesirichod A, Chaithirayanon S, Chaikul T, et al. The randomized trials of $10 \%$ urea cream and $0.025 \%$ tretinoin cream in the treatment of acanthosis nigricans [published online January 3, 2020]. J Dermatolog Treat. doi:10.1080/09546634.2019.1708855

19. Ragunatha S, Anitha B, Inamadar AC, et al. Cutaneous disorders in 500 diabetic patients attending diabetic clinic. Indian J Dermatol. 2011;56:160-164.

20. Morgan AJ, Schwartz RA. Diabetic dermopathy: a subtle sign with grave implications. J Am Acad Dermatol. 2008;58:447-451.

21. George SM, Walton S. Diabetic dermopathy. Br J Diabetes. 2014;14:95-97.

22. Bustan RS, Wasim D, Yderstræde KB, et al. Specific skin signs as a cutaneous marker of diabetes mellitus and the prediabetic state-a systematic review. Dan Med J. 2017;64:A5316.

23. McCash S, Emanuel PO. Defining diabetic dermopathy. J Dermatol. 2011;38:988-992. 
24. Brugler A, Thompson S, Turner S, et al. Skin blood flow abnormalities in diabetic dermopathy. J Am Acad Dermatol. 2011;65:559-563.

25. Sattar MA, Diab S, Sugathan TN, et al. Scleroedema diabeticorum: a minor but often unrecognized complication of diabetes mellitus. Diabet Med. 1988;5:465-468.

26. Venencie PY, Powell FC, Su WP, et al. Scleredema: a review of thirtythree cases. J Am Acad Dermatol. 1984;11:128-134.

27. Yosipovitch G, Hodak E, Vardi P, et al. The prevalence of cutaneous manifestations in IDDM patients and their association with diabetes risk factors and microvascular complications. Diabetes Care. 1998; 21:506-509.

28. Ferreli C, Gasparini G, Parodi A, et al. Cutaneous manifestations of scleroderma and scleroderma-like disorders: a comprehensive review. Clin Rev Allergy Immunol. 2017;53:306-336.

29. Martín C, Requena L, Manrique K, et al. Scleredema diabeticorum in a patient with type 2 diabetes mellitus. Case Rep Endocrinol. 2011;2011:560273.

30. Gkogkolou P, Böhm M. Advanced glycation end products: key players in skin aging? Dermatoendocrinol. 2012;4:259-270.

31. Nguyen HP, Katta R. Sugar sag: glycation and the role of diet in aging skin. Skin Therapy Lett. 2015;20:1-5

32. Uribarri J, Woodruff S, Goodman S, et al. Advanced glycation end products in foods and a practical guide to their reduction in the diet. J Am Diet Assoc. 2010;110:911-916.e912.

33. Tran K, Boyd KP, Robinson MR, et al. Scleredema diabeticorum. Dermatol Online J. 2013;19:20718.

34. Nakajima K, Iwagaki M, Ikeda M, et al. Two cases of diabetic scleredema that responded to PUVA therapy. J Dermatol. 2006;33:820-822.

35. Xiao T, Yang Z-H, He C-D, et al. Scleredema adultorum treated with narrow-band ultraviolet B phototherapy. J Dermatol. 2007;34:270-272.

36. Kokpol C, Rajatanavin N, Rattanakemakorn P. Successful treatment of scleredema diabeticorum by combining local PUVA and colchicine: a case report. Case Rep Dermatol. 2012;4:265-268.

37. Sanli H, Akay BN, Sen BB, et al. Acquired ichthyosis associated with type 1 diabetes mellitus. Dermatoendocrinol. 2009;1:34-36.

38. Patel N, Spencer LA, English JC 3rd, et al. Acquired ichthyosis. J Am Acad Dermatol. 2006;55:647-656.

39. Oji V, Traupe H. Ichthyosis: clinical manifestations and practical treatment options. Am J Clin Dermatol. 2009;10:351-364.

40. Shah R, Jindal A, Patel N. Acrochordons as a cutaneous sign of metabolic syndrome: a case-control study. Ann Med Health Sci Res. 2014;4:202-205.

41. Rasi A, Soltani-Arabshahi R, Shahbazi N. Skin tag as a cutaneous marker for impaired carbohydrate metabolism: a case-control study. Int J Dermatol. 2007;46:1155-1159.

42. Kahana M, Grossman E, Feinstein A, et al. Skin tags: a cutaneous marker for diabetes mellitus. Acta Derm Venereol. 1987;67:175-177.

43. Tamega Ade A, Aranha AM, Guiotoku MM, et al. Association between skin tags and insulin resistance. An Bras Dermatol. 2010;85:25-31.

44. Senel E, Salmanoğlu M, Solmazgül E, et al. Acrochordons as a cutaneous sign of impaired carbohydrate metabolism, hyperlipidemia, liver enzyme abnormalities and hypertension: a case-control study [published online December 21, 2011]. J Eur Acad Dermatol Venereol. doi:10.1111/j.1468-3083.2011.04396.x

45. Köseoğlu HG, Bozca BC, Basşorgun C, et al. The role of insulin-like growth factor in acrochordon etiopathology. BMC Dermatol. 2020;20:14.

46. Singh SK, Agrawal NK, Vishwakarma AK. Association of acanthosis nigricans and acrochordon with insulin resistance: a cross-sectional hospital-based study from North India. Indian J Dermatol. 2020; 65:112-117.

47. Margolis J, Margolis LS. Letter: skin tags — a frequent sign of diabetes mellitus. N Engl J Med. 1976;294:1184.

48. González-Saldivar G, Rodríguez-Gutiérrez R, Ocampo-Candiani J, et al. Skin manifestations of insulin resistance: from a biochemical stance to a clinical diagnosis and management. Dermatol Ther (Heidelb). 2017;7:37-51.
49. Ellis DL, Nanney LB, King LE Jr. Increased epidermal growth factor receptors in seborrheic keratoses and acrochordons of patients with the dysplastic nevus syndrome. J Am Acad Dermatol. 1990;23 (6 pt 1):1070-1077.

50. Hirt PA, Castillo DE, Yosipovitch G, et al. Skin changes in the obese patient. J Am Acad Dermatol. 2019;81:1037-1057.

51. Yosipovitch G, Mevorah B, Mashiach J, et al. High body mass index, dry scaly leg skin and atopic conditions are highly associated with keratosis pilaris. Dermatology. 2000;201:34-36.

52. Thomas M, Khopkar US. Keratosis pilaris revisited: is it more than just a follicular keratosis? Int J Trichology. 2012;4:255-258.

53. Gruber R, Sugarman JL, Crumrine D, et al. Sebaceous gland, hair shaft, and epidermal barrier abnormalities in keratosis pilaris with and without filaggrin deficiency. Am J Pathol. 2015;185:1012-1021.

54. Barth JH, Wojnarowska F, Dawber RP. Is keratosis pilaris another androgen-dependent dermatosis? Clin Exp Dermatol. 1988;13:240-241.

55. Hwang S, Schwartz RA. Keratosis pilaris: a common follicular hyperkeratosis. Cutis. 2008;82:177-180.

56. Poskitt L, Wilkinson JD. Natural history of keratosis pilaris. $\mathrm{Br} \mathrm{J}$ Dermatol. 1994;130:711-713.

57. Maghfour J, Ly S, Haidari W, et al. Treatment of keratosis pilaris and its variants: a systematic review [published online September 14, 2020]. J Dermatolog Treat. doi:10.1080/09546634.2020.1818678

58. O'Toole EA, Kennedy U, Nolan JJ, et al. Necrobiosis lipoidica: only a minority of patients have diabetes mellitus. Br J Dermatol. 1999;140:283-286.

59. Muller SA, Winkelmann RK. Necrobiosis lipoidica diabeticorum. a clinical and pathological investigation of 171 cases. Arch Dermatol. 1966;93:272-281.

60. Reid SD, Ladizinski B, Lee K, et al. Update on necrobiosis lipoidica: a review of etiology, diagnosis, and treatment options. J Am Acad Dermatol. 2013;69:783-791.

61. Hashemi DA, Brown-Joel ZO, Tkachenko E, et al. Clinical features and comorbidities of patients with necrobiosis lipoidica with or without diabetes. JAMA Dermatology. 2019;155:455-459.

62. Ngo B, Wigington G, Hayes K, et al. Skin blood flow in necrobiosis lipoidica diabeticorum. Int J Dermatol. 2008;47:354-358.

63. Zhang AJ, Garret M, Miller S. Bullosis diabeticorum: case report and review. N Z Med J. 2013;126:91-94.

64. Larsen $\mathrm{K}$, Jensen $\mathrm{T}$, Karlsmark $\mathrm{T}$, et al. Incidence of bullosis diabeticorum - a controversial cause of chronic foot ulceration. Int Wound J. 2008;5:591-596.

65. El Fekih N, Zéglaoui F, Sioud A, et al. Bullosis diabeticorum: report of ten cases. Tunis Med. 2009;87:747-749.

66. Lipsky BA, Baker PD, Ahroni JH. Diabetic bullae: 12 cases of a purportedly rare cutaneous disorder. Int J Dermatol. 2000;39:196-200.

67. Lopez PR, Leicht S, Sigmon JR, et al. Bullosis diabeticorum associated with a prediabetic state. South Med J. 2009;102:643-644.

68. Muhlemann MF, Williams DR. Localized granuloma annulare is associated with insulin-dependent diabetes mellitus. $\mathrm{Br} J$ Dermatol. 1984;111:325-329.

69. Haim S, Friedman-Birnbaum R, Haim N, et al. Carbohydrate tolerance in patients with granuloma annulare. $\mathrm{Br} J$ Dermatol. 1973;88:447-451.

70. Dabski K, Winkelmann RK. Generalized granuloma annulare: clinical and laboratory findings in 100 patients. J Am Acad Dermatol. 1989;20:39-47.

71. Agrawal P, Pursnani N, Jose R, et al. Granuloma annulare: a rare dermatological manifestation of diabetes mellitus. J Family Med Prim Care. 2019;8:3419-3421.

72. Studer EM, Calza AM, Saurat JH. Precipitating factors and associated diseases in 84 patients with granuloma annulare: a retrospective study. Dermatology. 1996;193:364-368.

73. Spicuzza L, Salafia S, Capizzi A, et al. Granuloma annulare as first clinical manifestation of diabetes mellitus in children: a case report. Diabetes Res Clin Pract. 2012;95:E55-E57.

74. Wang J, Khachemoune A. Granuloma annulare: a focused review of therapeutic options. Am J Clin Dermatol. 2018;19:333-344. 